\title{
A produção acadêmico-científica do Brasil na área das altas habilidades/superdotação no período de 1987 a 2011
}

\author{
Miguel Claudio Moriel Chacon* \\ Barbara Amaral Martins**
}

\section{Resumo}

Entre os alunos com necessidades educacionais especiais, sujeitos da educação especial, encontram-se aqueles que apresentam altas habilidades/superdotação, um fenômeno complexo que demanda o envolvimento de profissionais e pesquisadores da área educacional a fim de favorecer o desenvolvimento da potencialidade destes alunos. Nesse sentido, objetivamos identificar e analisar teses e dissertações que se propõem a investigar a temática das altas habilidades/superdotação, verificando a participação da área da Educação nessas pesquisas. O estudo se deu por meio de levantamento bibliográfico, norteado pelas seguintes questões: As pesquisas sobre altas habilidades/superdotação vêm crescendo nos últimos anos? Qual é a participação da área da Educação nestas pesquisas? Quais os assuntos relacionados às altas habilidades/superdotação abordados na Educação? A quais instituições estes pesquisadores estão vinculados? Os resultados nos mostram que as pesquisas apresentam uma tendência crescente e que há predomínio da área da Educação nesta produção científica. No entanto, há um desequilíbrio entre as instituições que se propõe a investigar a temática nas regiões brasileiras, bem como entre os assuntos abordados por estas pesquisas sobre altas habilidades/superdotação.

Palavras-chave: Altas habilidades; Superdotação; Educação Especial; Educação inclusiva.

* Professor Doutor da Universidade Estadual Paulista (UNESP), Campus de Marília, Marília, São Paulo, Brasil.

** Mestre em Educação pela Universidade Estadual Paulista (UNESP), Campus de Marília, Marília, São Paulo, Brasil. 


\section{Academic scientific-production in Brazil in the area of high abilities/giftedness on the period from 1987 to 2011}

\section{Abstract}

Among students with special educational needs, subjects of special education, are those with high ability/giftedness, a complex phenomenon that requires the participation of education professionals and researchers to foster the potential of development of these students. In this sense, we aimed to identify and analyze thesis and dissertations that they propose to investigate the theme high ability/giftedness, verifying participation of the area of education in these studies. The study was done through a literature review, guided by the following questions: Have the researches on high ability/giftedness been growing in recent years? What is the participation of education area in those researches? What are the issues related to high ability/ giftedness addressed in Education? The results show that the institutions present an increasing trend and there is a predominance of education area in this scientific production. However, there is an imbalance between the institutions that aim to investigate the theme in Brazilian regions, as well as among the cases covered by these researches on high ability/giftedness.

Keywords: High ability/giftedness; High ability; Giftedness; Special Education; Full Inclusion.

\section{Introdução}

É notório o destaque dado, no cenário nacional, à educação especial no decorrer dos últimos anos, o que se deve, principalmente, à implantação, no Brasil, a partir da década de 90, de uma política nacional de educação inclusiva, o que não implica no fim da educação especial, mas em sua aproximação com a educação regular, de modo a possibilitar o entrelaçamento entre esses dois sistemas, visando proporcionar oportunidades equitativas de aprendizagem a todos alunos (NARDI, 2007). A inclusão escolar requer que a atenção educacional especializada seja oferecida aos alunos com necessidades educacionais especiais na própria escola de ensino regular, com o propósito de evitar a segregação social de parte da população educacional.

A Lei de Diretrizes e Bases da Educação Nacional (LDB), nํ․ 9.394/96, dispõe em seu artigo $58^{\circ}$ que a educação especial é "a modalidade de educação escolar, oferecida preferencialmente na rede regular de ensino, para educandos portadores de necessidades especiais" (BRASIL, 1996, p. 43). A referida Lei garante em seu artigo 59ํㅡㄹ inciso I, que os sistemas de ensino assegurarão a esses alunos, "currículos, métodos, técnicas, recursos educativos e organização específicos, para atender às suas necessidades" (BRASIL, 1996, p. 44).

Entre os educandos com necessidades educacionais especiais encontram-se aqueles que possuem dificuldades acentuadas de aprendizagem decorrentes tanto de 
disfunções, limitações ou deficiências, quanto de causas não orgânicas específicas; os que utilizam linguagens e códigos diferenciados para se comunicarem e aqueles com altas habilidades/superdotação, grande facilidade e rapidez em aprender (BRASIL, 2001).

Dentre esses educandos que podem ser classificados como alunos com necessidades educacionais especiais, os alunos com altas habilidades/superdotação não estão entre os que, ao longo da história, mais receberam atenção por parte da mídia, das políticas governamentais para a educação ou mesmo da comunidade acadêmica. Contudo, é possível constatar uma tendência de crescimento, nos estudos relacionados a essa temática, na medida em que aumenta o envolvimento de pesquisadores de diferentes áreas com a mesma.

O norte-americano Joseph Renzulli, um dos teóricos mais conhecidos na área das altas habilidades/superdotação, acredita que a superdotação seja fruto da interligação de três traços: habilidade acima da média, comprometimento com a tarefa que constitui uma refinada forma de motivação - e criatividade. Para ele, é apenas na intersecção desses três traços que se encontra a produção ou criação superior. Porém, para ele a superdotação posse ser transitória (RENZULLI, 1978, p. 182).

Muitos alunos que apresentam altas habilidades/superdotação passam despercebidos pelo processo de escolarização, sem as necessárias oportunidades para desenvolver seu potencial, tampouco contribuir para o enriquecimento do ambiente educacional ao qual pertencem. Segundo Maia-Pinto e Fleith (2004), ao contrário do que acontece com alunos que apresentam rendimento escolar abaixo da média, que são rapidamente identificados e desfrutam da concepção amplamente divulgada no ambiente escolar, de que necessitam de atendimento diferenciado voltado ao atendimento de suas peculiaridades, são oferecidas poucas oportunidades para que os alunos que se destacam por suas potencialidades possam desenvolver tais habilidades. "Sem estímulo, essa pessoa pode desprezar seu potencial elevado e apresentar frustração e inadequação ao meio" (CUPERTINO, 2008, p. 13), motivo pelo qual a educação desses alunos não pode ser deixada ao acaso, uma vez que deve ser condizente com suas características, além de exigir sistematização e coerência. Para Cupertino (2008) essa criança é como qualquer outra, tendo o seu talento como diferencial principal.

Frente às necessidades educacionais especiais desses alunos e à complexidade do fenômeno altas habilidades/superdotação, faz-se necessário o envolvimento de profissionais e pesquisadores de diferentes áreas, bem como estudos mais aprofundados nas diferentes modalidades de alunos com necessidades educacionais especiais. Sendo assim, levantamos as seguintes questões: houve crescimento nas pesquisas no campo das altas habilidades/superdotação nos últimos anos? Qual é a participação da área da Educação nas pesquisas que envolvem essa temática? Quais os assuntos relacionados às altas habilidades/superdotação que são pesquisados na área da Educação? A quais instituições estes pesquisadores se encontram vinculados?

Assim, este trabalho tem por objetivo identificar teses e dissertações, da área da Educação, cujos autores se propuseram a investigar a temática das altas habilidades/superdotação. 


\section{Método}

Para a realização do levantamento bibliográfico que compõe este trabalho, delimitamos como base de dados o banco de teses e dissertações da Coordenação de Aperfeiçoamento de Pessoal de Nível Superior (CAPES).

Iniciamos a busca elencando como assunto a expressão "altas habilidades/superdotação" o que resultou na localização de 48 trabalhos. Em seguida, reiniciamos a busca utilizando a palavra "superdotação", que ocasionou a localização de 86 trabalhos, incluindo, entre eles, os 48 trabalhos localizados na busca anterior. Por fim, fizemos uma nova consulta, agora utilizando como palavras-chave "altas habilidades", obtendo como resultado 244 trabalhos listados, porém, apenas 74 abordavam a temática das altas habilidades/superdotação, destes, 23 não haviam aparecido nas buscas anteriores. Assim, encontramos um total de 109 trabalhos entre teses e dissertações. Essas 109 produções acadêmicas foram organizadas em quadros, onde destacamos: Instituição e Programa de Pós-Graduação aos quais se encontram vinculados, autor, título, objetivo e ano de defesa/apresentação. De posse dessas informações, pudemos analisar quantitativamente as produções em questão.

\section{Resultados}

Dos 109 trabalhos localizados, 70 são provenientes de Programas de Pós-Graduação em Educação (Educação, Educação Especial, Educação em Ciências e Matemática), 33 são de Programas de Pós-Graduação em Psicologia (Psicologia, Psicologia Escolar e do Desenvolvimento Humano, Processos do Desenvolvimento Humano e Saúde, Psicologia da Saúde) e 6 são de outros programas Pós-Graduação (Informática, Antropologia Social, Ciências da Comunicação, Sociologia, Ciências Médicas, Ciência da Motricidade Humana). Como mostra a Figura l:

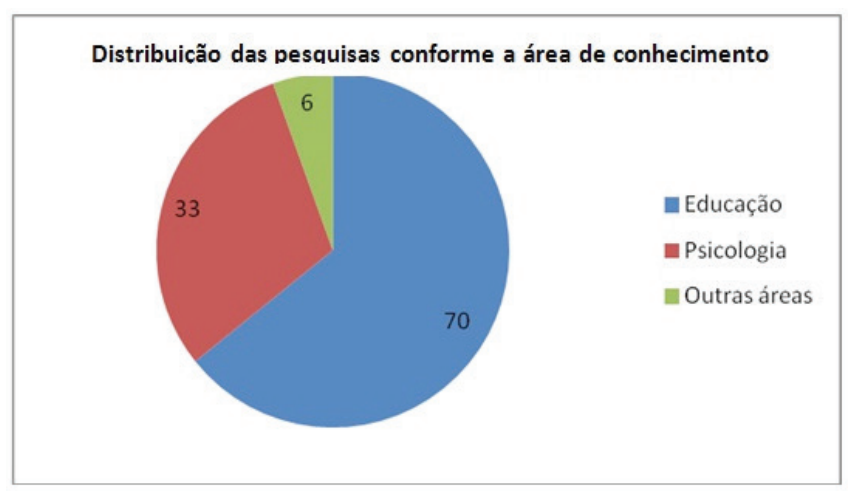

Figura 1 - Distribuição das pesquisas conforme a área de conhecimento.

Como se podem observar, as pesquisas acerca das altas habilidades/superdotação são predominantes na área da Educação, destacando-se de maneira significante em relação às outras áreas, embora a Psicologia desempenhe um importante papel na produção científica, enquanto as demais áreas do conhecimento ainda possuam pouca representatividade. 
Em relação ao período de produção dessas pesquisas, encontramos trabalhos desenvolvidos a partir de 1987, ausência entre 1990 e 1994, mas é a partir do ano de 1995 que a produção se intensifica. Ao observamos a Figura 2, notamos o considerável crescimento das produções acadêmicas.

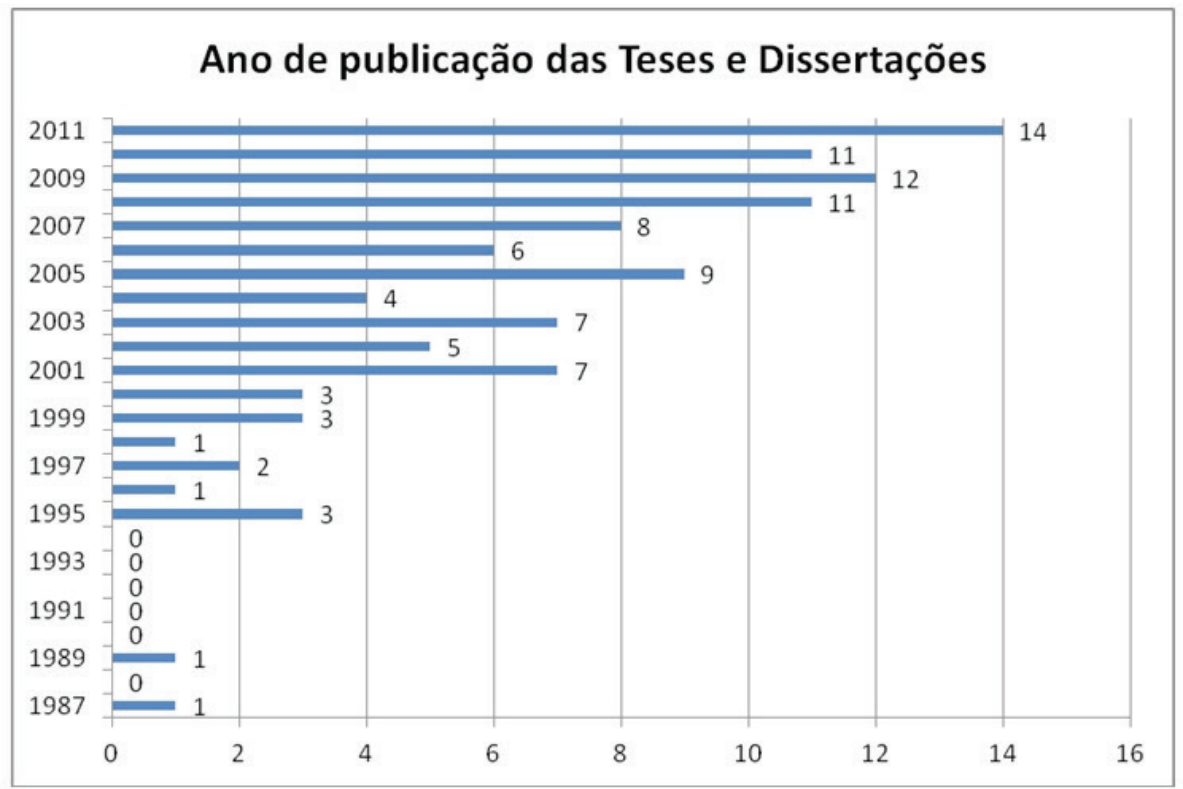

Figura 2 - Distribuição de teses e dissertações conforme o ano de publicação.

Além disso, ao analisarmos o Quadro 1, observamos, claramente, a ascensão do número de pesquisas sobre a temática das altas habilidades/superdotação nos três primeiros períodos e, em especial, no início do quarto período que abrange apenas dois anos.

\begin{tabular}{|c|cl|}
\hline Ano/Período & $\begin{array}{l}\text { Número } \\
\text { pesquisas }\end{array}$ & Autores/Ano \\
\hline $1987-89$ & 02 & Delou (1987); Osowski (1989) \\
\hline $1990-99$ & 10 & $\begin{array}{l}\text { Sabatella (1995); Costa (1995); Assis (1995); Maldaner (1996); Pi- } \\
\text { nho (1997); Becker (1997); Oliveira (1998); Sistëlos (1999); Câmara } \\
\text { (1999); Vieira (1999) }\end{array}$ \\
\hline
\end{tabular}


Continuação do Quadro 1

\begin{tabular}{|c|c|c|}
\hline 2000-09 & Costa (2000); Maia (2000); Ferreira (2000); Delou (2001); Bar- \\
& bosa (2001); Souza (2001); Franco (2001); Reis (2001); Duque \\
& (2001); Reis (2001); Pires (2002); Nicoloso (2002); Rocha (2002); \\
& Pinto (2002); Tsuboi (2002); Soares (2003); Viana (2003); Cha- \\
& gas (2003); Silva (2003); Bittelbrunn (2003); Aspesi (2003); Viana \\
& (2003); Guimarães (2004); Lustosa (2004); Ribeiro (2004); Pérez \\
& (2004); Moreira (2005); Viana (2005); Vieira (2005); Silva (2005); \\
& Melo (2005); Veigas (2005); Coutinho (2005); Ourofino (2005); \\
& Rangni (2005); Martins (2006); Jardim (2006); Reis (2006); Maga- \\
& lhães (2006); Germani (2006); Severo (2007); Rech (2007); Perai- \\
& no (2007); Oliveira (2007); Brandão (2007); Cruz (2007); Machado \\
& (2007); Cruz (2007); Arnal (2007); Reis (2008); Azevedo (2008); \\
& Chagas (2008); Fortes (2008); Perin (2008); Barbosa (2008); Bar- \\
& reto (2008); Pereira (2008); Pérez (2008); Pellegrino (2008); (Car- \\
& doso (2009); Delpretto (2009); Moraes (2009); Siqueira (2009); \\
& Silva (2009); Oliveira (2009); Oliveira (2009); Bifon (2009); Monte \\
& (2009); Santos (2009); Guimarães (2009); Negrini (2009); Moura \\
& (2009) \\
& Sakaguti (2010); Rabelo (2010); Bürkle (2010); Souza (2010); Peri- \\
& polli (2010); Lima (2010); Pereira (2010); Marques (2010); Fandino \\
& (2010); Gonçalves (2010); Fonseca (2010); Lima (2011); Arantes \\
& (2011); Trancoso (2011); Fernandes (2011); Correia (2011); Martins \\
& (2011); Anjos (20ll); Lamas (2011); Forno (2011); Dalosto (2011); \\
& Araújo (2011); Souza (2011); Batista (2011); Ourofino (2011). \\
\hline 2010-11 &
\end{tabular}

Quadro 1 - Distribuição do número de pesquisas conforme o ano/período de publicação.

$\mathrm{Na}$ distribuição do número total de pesquisas produzidas em cada período pelos seus respectivos anos, encontramos baixa produção no primeiro período, sendo uma em 1987 e outra em 1989. Já, entre 1990 e 1999 a média foi de uma pesquisa/ano e de 2000 a 2009, essa produção passou à média correspondente a mais de sete pesquisas/ano. Contudo, somente nos anos de 2010 e 201l, foram registradas 25 pesquisas, o que equivale uma média de aproximadamente 12 pesquisas/ano, evidenciando uma perspectiva de crescimento no número de pesquisas a serem registradas até o final de 2019, o que deverá ultrapassar as produções das décadas anteriores.

A partir de agora, mesmo reconhecendo a importância da contribuição dada pelas pesquisas de outras áreas, nos aprofundaremos nas produções dos Programas de Pós-Graduação em Educação. A fim de identificar os assuntos abordados nas investigações, criamos 14 categorias a partir da análise dos títulos e dos resumos. Essas categorias são: identificação ou caracterização de alunos com altas habilidades/superdotação; características desejáveis, formação e concepção de professores; salas de recursos, modelos e programas de atendimento especializado; práticas pedagógicas ou metodologias de ensino; análise documental e pesquisa bibliográfica; inclusão do aluno com altas habilidades/superdotação na classe regular; adultos com altas habilidades/superdotação; percepções e opiniões de pessoas com altas habilidades/superdotação; altas habilidades/superdotação associadas a outras necessidades educacionais especiais; o fenômeno bullying; pais e famílias de pessoas com altas habilidades/ superdotação; processos de aprendizagem do aluno com altas habilidades/superdotação; precocidade; o brincar. 
Em algumas situações, o trabalho parecia se encaixar em mais de uma categoria, no entanto, a leitura do resumo permitia visualizar a categoria com a qual havia maior aproximação. O quadro abaixo apresenta os 70 trabalhos da área da Educação, distribuídos nas categorias acima descritas:

\begin{tabular}{|l|c|}
\hline \multicolumn{1}{|c|}{ Categorias } & $\begin{array}{c}\mathrm{N}^{\circ} \text { de } \\
\text { pesquisas }\end{array}$ \\
\hline Identificação ou caracterização de alunos com altas habilidades/superdotação & 18 \\
\hline Salas de recursos, modelos e programas de atendimento especializado & 10 \\
\hline Percepções e opiniões de pessoas com altas habilidades/superdotação & 08 \\
\hline Análise documental e pesquisa bibliográfica & 07 \\
\hline Práticas pedagógicas ou metodologias de ensino & 06 \\
\hline Características desejáveis, formação e concepção de professores & 05 \\
\hline Inclusão do aluno com altas habilidades/superdotação na classe regular & 04 \\
\hline Processos de aprendizagem do aluno com altas habilidades/superdotação & 03 \\
\hline Pais e famílias de pessoas com altas habilidades/superdotação & 03 \\
\hline Adultos com altas habilidades/superdotação & 02 \\
\hline O fenômeno bullying & 01 \\
\hline altas habilidades/superdotação associadas a outras necessidades educacionais especiais & 01 \\
\hline Precocidade & 01 \\
\hline O brincar & 01 \\
\hline TOTAL & 70 \\
\hline
\end{tabular}

Quadro 2 - Distribuição das pesquisas da área de Educação de acordo com as categorias temáticas.

Do total de 70 pesquisas na área da Educação, 51,5\% concentram-se nas três primeiras categorias, com destaque para a categoria Identificação ou caracterização de alunos com altas habilidades/superdotação (18), seguido das categorias: salas de recursos, modelos e programas de atendimento especializado (10) e percepções e opiniões de pessoas com altas habilidades/superdotação (08). Por outro lado, 42,8\% se concentram nas sete categorias subsequentes e apenas 5,7\% nas quatro últimas categorias.

Quanto às instituições de origem destas pesquisas, encontramos estudos acerca da temática em todas as regiões do país, porém não com a mesma representatividade, como ilustrado na Figura 3: 


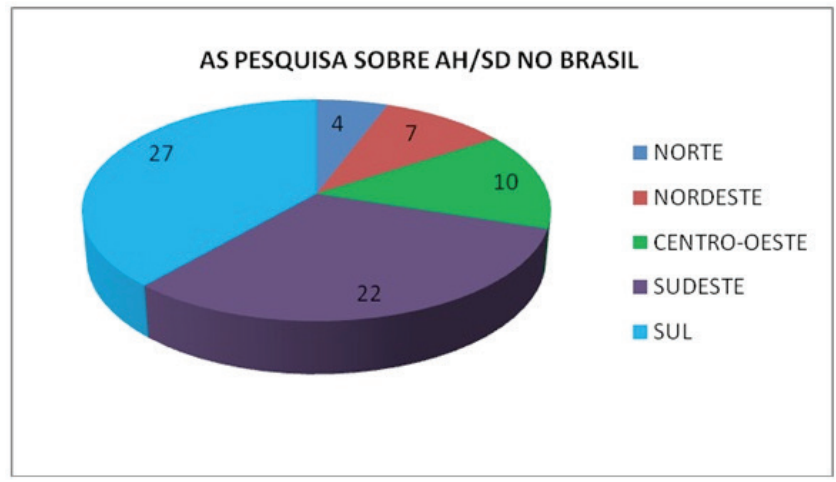

Figura 3 - Distribuição das pesquisas conforme a região do Brasil.

Como se pode observar no gráfico acima, a região Sul tem a maior representatividade nessas pesquisas com 27 produções acadêmicas, seguida pela região Sudeste com 22, e nas regiões Centro-Oeste, Nordeste e Norte foram realizadas respectivamente, dez, sete e quatro produções acadêmicas relacionadas à temática das altas habilidades/superdotação.

Quanto à distribuição dessas produções, conforme as Universidades de origem, como se pode ver na Figura 4, na região Norte, as quatro pesquisas identificadas são provenientes da Universidade Federal do Amazonas (UFAM), enquanto que, na região Nordeste, elas provêm de duas instituições distintas, as Universidades Federais do Piauí (UFPI) e a do Ceará (UFC), num total de sete pesquisas, ou seja, quase o dobro da região Norte.

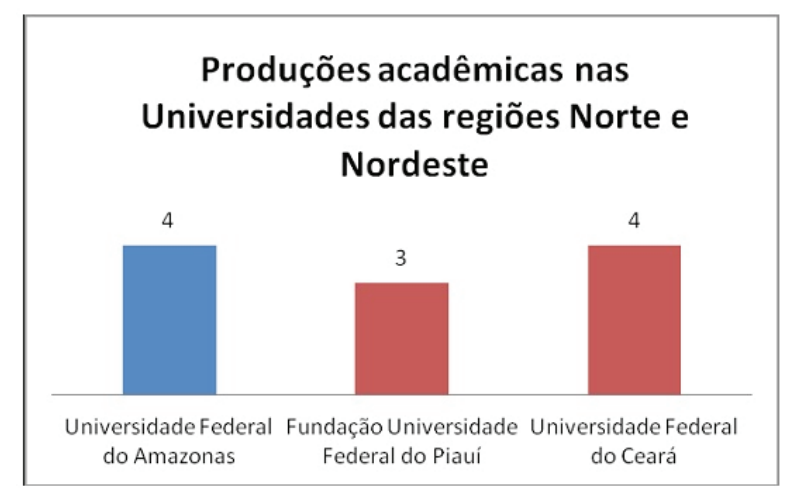

Figura 4 - Distribuição das produções acadêmicas nas regiões Norte e Nordeste.

Na região Centro-Oeste, como se pode ver na Figura 5, contamos com a participação de três Universidades e, entre elas, a que possui maior produção de Teses e Dissertação sobre altas habilidades/superdotação é a Universidade Católica de Brasília, com sete produções acadêmicas identificadas, seguida pelas Universidades Federais do Mato Grosso do Sul (UFMS) e Goiás (UFG) com duas e uma produções acadêmicas, respectivamente. 


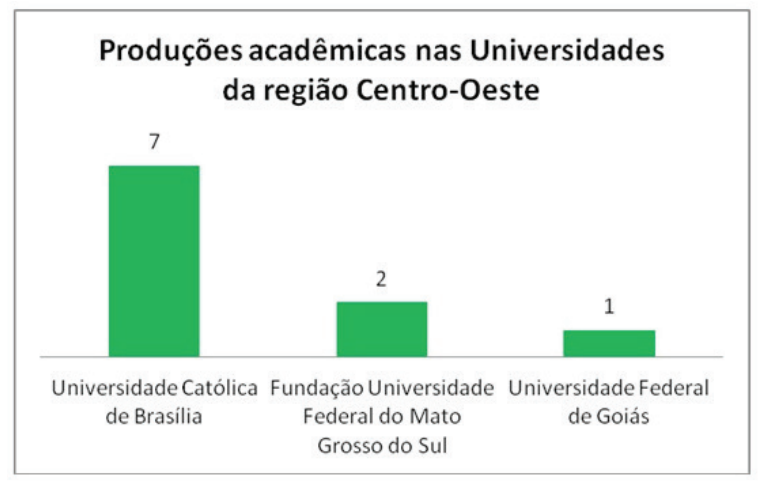

Figura 5 - Distribuição das produções acadêmicas na região Centro-Oeste.

Como se pode ver na Figura 6, a região Sudeste possui o maior número de Universidades, nas quais foram registradas 22 produções acadêmicas relacionadas com as altas habilidades/superdotação, sendo que, com exceção da Universidade Estadual do Rio de Janeiro, que, até o momento, lidera todas as universidades do país, as outras Universidades desta região desenvolveram uma quantidade pequena de pesquisas nessa área.

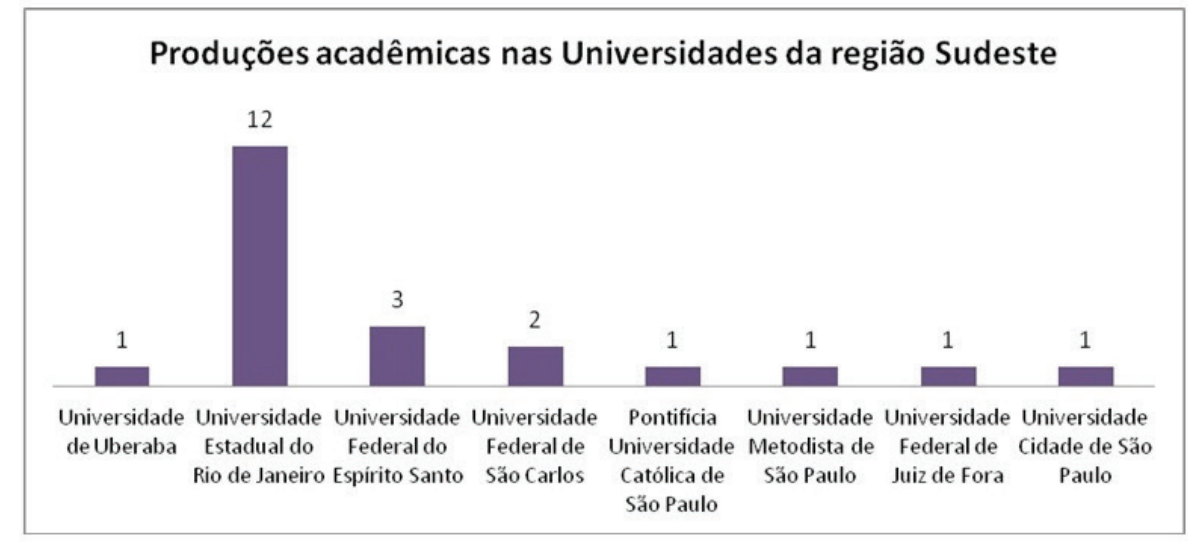

Figura 6 - Distribuição das produções acadêmicas na região Sudeste.

Na Figura 7, está representado o número de Teses e Dissertações produzidas na região Sul do país, dividido entre cinco instituições, as Universidades Federais de Santa Maria (UFSM), a do Rio Grande do Sul (UFRGS) e a do Paraná (UFPR) com respectivamente nove, sete e seis produções acadêmicas, seguidas pela Pontifícia Universidade Católica (PUC/RS), com três produções e a Universidade Estadual de Maringá (UEM) com duas. As Universidades Federais apresentam-se como as mais produtivas no que tange à temática em questão, havendo inclusive, certo equilíbrio entre suas pesquisas na área das altas habilidades/superdotação. 


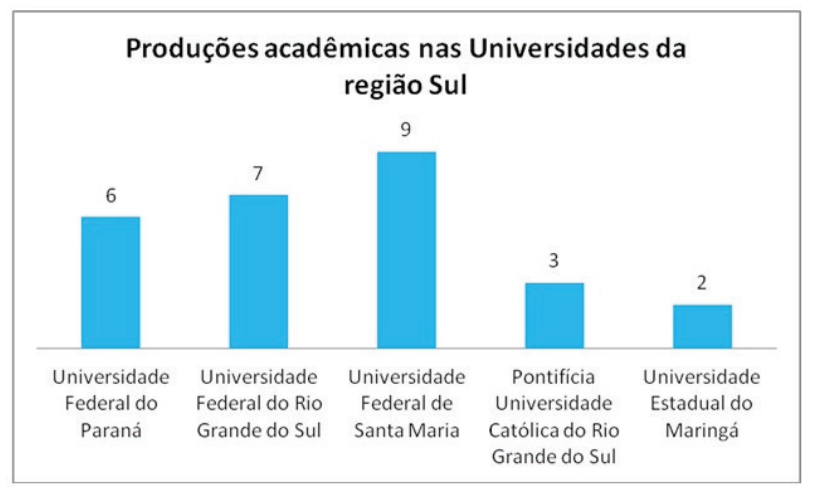

Figura 7 - Distribuição das produções acadêmicas na região Sul.

\section{Discussões}

Os resultados nos mostram que as pesquisas sobre a temática das altas habilidades/superdotação estão em constante crescimento e que a área da Educação se destaca de maneira significante em relação as outras áreas, embora a Psicologia desempenhe um importante papel na produção científica, e as demais áreas do conhecimento ainda possuam pouca representatividade. Essa discrepância pode ser explicada pelo fato de serem pesquisas cujos objetos de estudo são, na sua grande maioria, alunos com necessidades educacionais especiais (BRASIL 1996), o que coloca em evidência o maior interesse dos educadores que de outros profissionais, mas também pode ser pelo maior número de Programas de Pós-Graduação em Educação, são 183 programas devidamente reconhecidos pela CAPES até 2012, programas esses que concentram um maior número de profissionais interessados na temática das altas habilidades/ superdotação, pelo envolvimento que têm, tanto com a política nacional de educação especial (BRASIL, 2008), quanto com a legislação educacional (BRASIL, 1996, 2001, 2008, 2009, 2012a, 2012b).

Analisando a tendência de crescimento numérico de pesquisas sobre as altas habilidades/superdotação, a distribuição do número total de produção, em cada período, pelos seus respectivos anos, evidencia o crescimento a cada década e a perspectiva de um aumento ainda maior a ser registrado até o final de 2019, o que aponta para uma maior atenção dos pesquisadores a essa parcela do público alvo da educação especial definidos na política nacional de educação especial (BRASIL 2008). Este aumento, na produção, pode estar sendo influenciado pelos movimentos de organizações não governamentais como, por exemplo, o Conselho Brasileiro de Superdotação (ConBraSD), o aumento do número de professores orientadores interessados na temática das altas habilidades/superdotação nos Programas de Pós-Graduação, bem como a existência de projetos de extensão universitária ou de outra natureza e a presença maciça de todos esses profissionais e pós-graduandos em eventos científicos nacionais e internacionais, com participação em conferências, mesas redondas, mini-cursos, apresentações de trabalhos em forma de pôster ou oral, dentre outras possíveis variáveis. 
Por se tratar de Programas de Pós-Graduação em Educação, chama a atenção o baixo número de investigações a respeito das "Práticas pedagógicas ou metodologias de ensino" (seis), "Características desejáveis, formação e concepção de professores" (cinco), "Inclusão do aluno com altas habilidades/superdotação na classe regular" (quatro), e "Processos de aprendizagem do aluno com altas habilidades/superdotação" (três). A prioridade para a categoria "Identificação de alunos e o atendimento educacional especializado destinado dos alunos com altas habilidades/superdotação" evidencia o quanto é relevante identificar esses alunos, pois é, a partir daí, que se inicia a atenção educacional voltada as suas necessidades, porém, é preciso que estejamos atentos ao conhecimento científico produzido, para que possamos contribuir com seu avanço.

Queremos, aqui, evidenciar a ausência total de produção acadêmica, na área da Educação, relacionada à tecnologia, à exploração digital e a como a sociedade da informação afeta nossos jovens, uma vez que introduz novas maneiras de se relacionar "com a informação, com as novas tecnologias e uns com os outros." (PALFREY; GASSER, 2011, p. 23). Trata-se de uma temática que precisa ser urgentemente abordada, pois é parte da vida dos nossos alunos de hoje, denominados Nativos Digitais (PALFREY; GASSER, 2011). Outra categoria que ressaltamos a ausência está relacionada à identificação e trabalhos tendo como objeto de estudo o idoso com altas habilidades/superdotação, tema este que encontra terreno fértil para as investigações nos dias de hoje, pois se trata de uma categoria de pessoas que vem sendo estudada em suas diferentes dimensões. Spirduso (2005), em sua obra, Dimensões físicas do envelhecimento, trata do envelhecimento nos seus aspectos físicos e psicossociais, oferecendo um rico campo de abordagem sobre o assunto e que podem ser relacionados à temática aqui investigada.

Da mesma maneira e tão importante quanto o atendimento educacional especializado, talvez até mais complexo, é o processo de inclusão desses alunos nas classes de ensino regular, o que não justifica o predomínio de determinadas pesquisas, principalmente, porque ainda temos muito que investigar a respeito desse assunto tão antigo e ao mesmo tempo tão novo. Antigo porque na Grécia clássica, aqueles que apresentavam capacidade superior à média já causavam estranhamento e eram tidos como possuidores de um dom divino, e novo, pois, embora o primeiro estudo científico sobre a superdotação tenha ocorrido no ano de 1869, por Galton (ACEREDA; SASTRE, 1998), é na atualidade que o interesse por esse assunto se intensifica. Porém este permanece permeado por polêmicas e incertezas, a começar pelo próprio uso de termos e nomenclaturas que definem o fenômeno estudado, como: superdotação, dotação, talento, altas habilidades, altas habilidades/superdotação, além do fato de se tratar de um campo pouco considerado no que tange à Educação Especial e Inclusiva no Brasil (RANGNI; COSTA, 2011).

Em relação à distribuição das produções acadêmicas sobre a temática das altas habilidades/superdotação pelas Universidades brasileiras, foi possível averiguar que se concentram mais nas regiões Sul e Sudeste. Embora estas sejam as regiões com maior número de pesquisas sobre a temática em questão, este fato não justifica 
o desequilíbrio, pois a região Sudeste, que é onde se encontra grande parte dos cursos de Pós-graduação Stricto Sensu, só se aproxima da região Sul por conta da Universidade Estadual do Rio de Janeiro, que apresenta expressiva produção na área. E, se considerarmos que o Brasil possui 183 Programas de Pós-Graduação em Educação devidamente reconhecidos (CAPES, 2012) e, que destes, somente 19 desenvolveram pesquisas sobre altas habilidades/superdotação, constatamos o quanto ainda é pequeno o interesse por essa temática.

\section{Considerações finais}

O aluno que se destaca dos demais integrantes do grupo, seja por seu elevado potencial acadêmico ou em qualquer outra área de domínio, considerado pela legislação vigente aluno com altas habilidades/superdotação, requer tanto atenção educacional especializada quanto aquele que possui alguma outra necessidade educacional especial. A Educação brasileira não alcançou, ainda, as condições adequadas ao desenvolvimento máximo do potencial daqueles alunos, condições essas já bastante reconhecidas e oferecidas aos alunos com deficiência. No âmbito das produções acadêmicas, a área educacional é a que mais desenvolveu estudos sobre a temática das altas habilidades/superdotação.

Apesar de se tratar de um assunto pouco explorado pelos pesquisadores, há algumas décadas, os dados aqui apresentados evidenciam que este quadro vem se modificando e que a temática das altas habilidades/superdotação está despertando o interesse tanto dos pesquisadores orientadores quanto daqueles que buscam os Programas de Pós-Graduação Stricto Sensu, gerando, desta maneira, o aumento na produção acadêmica nessa área. Somado a isso, observamos ainda o aumento expressivo de Universidades que contemplam em seus Programas de Pós-Graduação trabalhos nessa área, sendo 12 Federais, seis Particulares e uma Estadual, além de outras que terão seus primeiros trabalhos defendidos após 2011.

No tocante aos assuntos pesquisados na área da Educação e relacionados à temática das altas habilidades/superdotação destacaram-se as categorias Identificação ou caracterização de alunos com altas habilidades/superdotação, salas de recursos, modelos e programas de atendimento especializado e percepções e opiniões de pessoas com altas habilidades/superdotação. Voltamos a enfatizar a ausência de produção acadêmica sobre a temática envolvendo a tecnologia, à exploração digital e como a sociedade da informação afeta nossos jovens, bem como à identificação e trabalhos tendo como objeto de estudo o idoso com altas habilidades/superdotação, categoria de pessoas que vem sendo estudada em suas diferentes dimensões.

Com a extinção das habilitações em educação especial em função da política nacional de inclusão, a formação específica nas diferentes modalidades da educação especial ficou atribuida a algumas disciplinas ou tópicos em disciplinas nos cursos de graduação, a cursos de Pós-Graduação Lato e Stricto Sansu, ou mesmo cursos de curta duração, ações essas insuficientes para que o profissional receba e trate com a competência necessária essa parcela da população educacional. Tal fato deve servir 
de subsídio para que os governantes tracem mais ações nos âmbitos da formação e do trabalho junto aos profissionais da educação e da saúde que atuam diretamente com pessoas nessas condições.

Evidenciamos, ainda, a necessidade da intensificação de pesquisas, bem como o envolvimento em maior número de outras áreas do conhecimento seja das Ciências Humanas, Exatas ou Sociais, com a temática aqui discutida, pois os educandos com altas habilidades/superdotação possuem potenciais que podem prestar contribuições significativas a nossa sociedade, em todos os domínios de conhecimento.

\section{Referências}

ACEREDA, A; SASTRE, S. La superdotación. Madrid: Síntesis Psicología, 1998.

ANJOS, I. R. S. Dotação e talento: concepções reveladas em dissertações e teses no Brasil. Tese (Doutorado em Educação Especial). 190f. Programa de Pós-Graduação em Educação Especial, Universidade Federal de São Carlos, 2011.

ANTIPOFF, C. A; CAMPO, R. H. F. Superdotação e seus mitos. Revista Semestral da Associação Brasileira de Psicologia Escolar e Educacional, São Paulo, v. 14, n. 2, p. 301-309, jul.-dez. 2010.

ARANTES, D. R. B. Uma investigação sobre pessoas com altas habilidades/superdotação: dialogando com Marion Milner. Dissertação (Mestrado em Psicologia). 108f. Programa de Pós-Graduação em Psicologia, Pontifícia Universidade Católica de São Paulo, 2011.

ARAUJO, M. R. Identificação e encaminhamento de alunos com indicadores de altas habilidades/ superdotação na escola pública do município de Fortaleza: proposta para a atuação de professores do atendimento educacional especializado. Dissertação (Mestrado em Educação). 1llf. Programa de Pós-Graduação em Educação, Universidade Federal do Ceará, 2011.

ARNAL, L. S. P. Educação escolar inclusiva: a prática pedagógica nas salas de recursos. Dissertação (Mestrado em Educação). 133f. Programa de Pós-Graduação em Educação, Universidade Estadual de Maringá, 2007.

ASPESI, C. C. Processos Familiares Relacionados ao Desenvolvimento de Comportamentos de superdotação em Crianças de Idade Pré-Escolar. Dissertação (Mestrado em Psicologia). 86f. Programa de Pós-Graduação em Psicologia, Universidade de Brasília, 2003.

ASSIS, A. L. A. O aluno superdotado nas camadas populares. Dissertação (Mestrado em Educação). 5lf. Programa de Pós-Graduação em Educação, Universidade do Estado do Rio de Janeiro,1995.

AZEVEDO, S. M. L. Altas habilidades: mitos e dilemas na indicação para atendimento. Dissertação (Mestrado em Psicologia). 128f. Programa de Pós-Graduação em Psicologia, Universidade Salgado de Oliveira, 2008.

BARBOSA, M. C. D. L. Inteligência prática na sala de aula: a inclusão das diferenças e o compartilhar das altas habilidades. Dissertação (Mestrado em Educação). 159f. Programa de Pós-Graduação em Educação, Universidade do Estado do Rio de Janeiro, 2001.

Programa de enriquecimento de base cognitivo-comportamental mediando o transtorno obsessivo compulsivo /TOC de um estudante com altas habilidades na escola regular: um estudo de caso. Tese (Doutorado em Ciência Médicas). 243f. Programa de Pós-Graduação em Ciência Médicas, Universidade do Estado do Rio de Janeiro, 2008.

BARRETO, C. M. P. F. Altas Habilidades / Superdotação: Representações Sociais dos professores do colégio Pedro II. Dissertação (Mestrado em Psicologia). 18lf. Programa de Pós-Graduação em Psicologia, Universidade Salgado de Oliveira, 2008.

BATISTA, S. L. Uma experiência com estudante do ensino fundamental com indícios de Altas Habilidades/Superdotação: contribuições das tecnologias computacionais para o enriquecimento do processo de ensino e aprendizagem. Dissertação (Mestrado em Educação). 186f. Programa de Pós-Graduação em Educação, Universidade Federal do Espírito Santo, 2011. 
BECKER, M. A. A. Educação Especial: Estímulo Ambiental e Potencial para Altas Habilidades em Pré-Escolares. Dissertação (Mestrado em Psicologia). 189f. Programa de Pós-Graduação em Psicologia, Pontifícia Universidade Católica do Rio Grande do Sul, 1997.

BIFON, M. F. A constituição social da potencialidade humana: contribuição para o estudo da superdotação. Dissertação (Mestrado em Psicologia). 168f. Programa de Pós-Graduação em Psicologia, Universidade Estadual de Maringá, 2009.

BITTELbRUNN, I. B. A. O silêncio da Escola Pública: Um estudo sobre os programas de atendimento aos alunos com indicadores de superdotação no Estado de Mato Grosso do Sul. Dissertação (Mestrado em Educação). 99f. Programa de Pós-Graduação em Educação, Fundação Universidade Federal de Mato Grosso do Sul, 2003.

BRANDÃO, S. H. A. Alunos com altas habilidades/superdotação: o atendimento em sala de recursos no estado do Paraná. Dissertação (Mestrado em Educação). 119f. Programa de Pós-Graduação em Educação, Universidade Estadual de Maringá, 2007.

BRASIL. Ministério da Educação. Política Nacional da Educação Especial na Perspectiva da Educação Inclusiva. Brasília: MEC/SEESP, 2008.

Diretrizes operacionais da Educação Especial para o Atendimento Educacional Especializado na Educação Básica. Brasília: MEC/SEESP, 2009.

BRASIL. Ministério da Educação, Lei n.o 9394, de 20 de dezembro de 1996. Estabelece as diretrizes e bases da educação nacional. Disponível em: 〈http://www.planalto.gov.br〉. Acesso em: 01 jun. 2012a.

Resolução CNE/CEB no‥ 02, de 11 de setembro de 2001. Institui Diretrizes Nacionais para a Educação Especial na Educação Básica. Disponível em: 〈http://portal.mec.gov.br/cne/arquivos/pdf/CEB0201. pdf〉. Acesso em: 01 jun. 2012b.

BÜRKLE, T. S. A Sala de Recursos como suporte à Educação Inclusiva no Município do Rio de Janeiro: das propostas legais à prática cotidiana. Dissertação (Mestrado em Educação). 147f. Programa de Pós-Graduação em Educação, Universidade do Estado do Rio de Janeiro, 2010.

CÂMARA C. G. Auto-alfabetização precoce: indício de superdotação ou resposta a um ambiente rico em estímulos?. Dissertação (Mestrado em Psicologia escolar e do desenvolvimento humano). 159f. Programa de Pós-Graduação em Psicologia escolar e do desenvolvimento humano, Universidade de São Paulo, 1999.

CAPES. Mestrados/Doutorados Reconhecidos. Disponível em: ‘http://www.capes.gov.br/cursos-recomendados/>. Acesso em: 17 jul. 2012.

CARDOSO, A. O. G. Identificando Adolescentes em Situação de Rua com Potencial para Altas Habilidades/Superdotação. Dissertação (Mestrado em Educação). 136f. Programa de Pós-Graduação em Educação, Universidade Federal do Amazonas, 2009.

CHAGAS, J. F. Características familiares relacionadas ao desenvolvimento de comportamentos de superdotação em alunos de nível sócio-econômico desfavorecido. Dissertação (Mestrado em Psicologia). 179f. Programa de Pós-Graduação em Psicologia, Universidade de Brasília, 2003.

Adolescentes talentosos: características individuais e familiares. Tese (Doutorado em Processos de desenvolvimento humano e saúde). 224f. Programa de Pós-Graduação em Processos de desenvolvimento humano e saúde, Universidade de Brasília, 2008.

CORREIA, G. B. O autoconceito de estudantes com altas habilidades/superdotação na vivência da adolescência. Tese (Doutorado em Educação). 226f. Programa de Pós-Graduação em Educação, Universidade Federal do Paraná, 2011.

COSTA, M. R. N. Um estudo sobre o adolescente portador de altas habilidades: seu "olhar" sobre si mesmo. Seu "olhar" sobre o "olhar" do outros. Dissertação (Mestrado em Educação). 226f. Programa de Pós-Graduação em Educação, Universidade Federal do Rio Grande do Sul, 2000.

COSTA, P. Y. M. A relação entre narcisismo e genialidade. Dissertação (Mestrado em Psicologia Clínica). 100f. Programa de Pós-Graduação em Psicologia Clínica, Pontifícia Universidade Católica do Rio de Janeiro, 1995.

COUTINHO, M. M. B. Altas habilidades: o PRISMA da família. Dissertação (Mestrado em Educação). 120f. Programa de Pós-Graduação em Educação, Universidade do Estado do Rio de Janeiro, 2005. 
CRUZ, C. A construção de práticas de atendimento ao aluno com altas habilidades/superdotação no Espírito Santo: um estudo sobre o projeto de atendimento ao aluno talentoso - PAAT. Dissertação (Mestrado em Educação). lllf. Programa de Pós-Graduação em Educação, Universidade Federal do Espírito Santo, 2007.

CRUZ, J. O. Mulher na ciência: representação ou ficção. Tese (Doutorado em Ciências da Comunicação). 242f. Programa de Pós-Graduação em Ciências da Comunicação, Universidade de Brasília, 2008.

CUPERTINO, C.M.B. (Org.). Um olhar para as altas habilidades: construindo caminhos/Secretaria da Educação. São Paulo: FDE, 2008.

DALOSTO, M. M. O aluno com altas habilidades/ superdotação e o bullying: manifestações, prevalências e impactos. Dissertação (Mestrado em Psicologia). 116f. Programa de Pós-Graduação em Psicologia, Universidade Católica de Brasília, 2011.

DELOU. C. M. C. Identificação de superdotados: uma alternativa para sistematização da observação de professores em sala de aula. Dissertação (Mestrado em Psicologia). 166f. Programa de Pós-Graduação em Psicologia, Universidade do Estado do Rio de Janeiro, 1987.

. Sucesso e fracasso escolar de alunos considerados superdotados: um estudo sobre a trajetória es$\overline{c o l a r}$ de alunos que receberam atendimento em sala de recursos de escolas da rede pública de ensino. Tese (Doutorado em Educação: história, política, sociedade). 238f. Programa de Pós-Graduação em Educação: história, política, sociedade, Pontifícia Universidade Católica de São Paulo, 2001.

DELPRETTO, B. M. L. A pessoa com altas habilidades/superdotação adulta: análises do processo de escolarização com elementos da contemporaneidade. Dissertação (Mestrado em Educação). 110f. Programa de Pós-Graduação em Educação, Universidade Federal de Santa Maria, 2009.

DUQUE, F. H. O. Com a palavra os portadores de altas habilidades - Características, gostos e necessidades. Dissertação (Mestrado em Educação). 132f. Programa de Pós-Graduação em Educação, Universidade do Estado do Rio de Janeiro, 2001.

FANDINO, D. B. O aluno com altas habilidades/superdotação um estudo exploratório. Dissertação (Mestrado em Educação). 84f. Programa de Pós-Graduação em Educação, Universidade Metodista de São Paulo, 2010.

FERNANDES, G. S. Entre uma sala e outra: Uma experiência etnográfica a partir das salas de recursos para altas habilidades/superdotação em Porto Alegre, Rio Grande do Sul. Dissertação (Mestrado em Antropologia Social). 84f. Programa de Pós-Graduação em Antropologia Social, Universidade Federal do Rio Grande do Sul, 2011.

FERREIRA, A. S. Representação social de escola segundo alunos superdotados. Dissertação (Mestrado em Psicologia). 78f. Programa de Pós-Graduação em Psicologia, Universidade Federal do Espírito Santo, 2000.

FONSECA, D. F. A identificação de alunos com altas habilidades/superdotação em uma escola da rede particular de ensino de Teresina-Piauí. Dissertação (Mestrado em Educação). 110f. Programa de Pós-Graduação em Educação, Fundação Universidade Federal do Piauí, 2010.

FORNO, L. F. Precocidade na Educação Infantil: E agora professoras? Dissertação (Mestrado em Educação). l19f. Programa de Pós-Graduação em Educação, UFSM, 2011.

FORTES, C. C. Contribuições do PIT - Programa de Incentivo ao Talento no processo de aprendizagem e desenvolvimento de um aluno com altas habilidades. Dissertação (Mestrado em Educação). 15lf. Programa de Pós-Graduação em Educação, Universidade Federal de Santa Maria, 2008.

FRANCO, E. T. S. Capacidade acadêmica elevada: experiências singulares de cinco alunos na escola fundamental. Dissertação (Mestrado em Educação). 142f. Programa de Pós-Graduação em Educação, Universidade Federal de Juiz de Fora, 2001.

GERMANI, L. M. B. Características de altas habilidades/superdotação e de déficit de atenção/hiperatividade: uma contribuição à família e à escola. Dissertação (Mestrado em Educação). 178f. Programa de Pós-Graduação em Educação, Pontifícia Universidade Católica/RS, 2006.

GONÇALVES, F. C. Estudo comparativo entre alunos superdotados e não superdotados em relação à criatividade, inteligência e percepção de clima de sala de aula para criatividade. Dissertação (Mestrado em Processos de desenvolvimento humano e saúde). 94f. Programa de Pós-Graduação em Processos de desenvolvimento humano e saúde, Universidade de Brasília, 2010.

Revista Educação Especial | v. 27 | n. 49 | p. 353-372| maio/ago. 2014

Santa Maria 
GUIMARÃES, A. C. M. Um estudo sobre a formação do professor e a inclusão da criança superdotada. Dissertação (Mestrado em Educação). 150f. Programa de Pós-Graduação em Educação, Universidade de Uberaba, 2004.

GUIMARÃES, T. G. Estudo de caso de um aluno superdotado com transtorno de asperger: desenvolvimento, características cognitivas e sócio-emocionais. Dissertação (Mestrado em Psicologia). $93 \mathrm{f}$. Programa de Pós-Graduação em Psicologia, Universidade Católica de Brasília, 2009.

JARDIM, G. L. M. Inteligência e conhecimento geral e atual de crianças escolares de altas habilidades cognitivas. Dissertação (Mestrado em Psicologia). 8lf. Programa de Pós-Graduação em Psicologia, Universidade Federal de Minas Gerais, 2006

LAMAS, K. C. A. Desenvolvimento ocupacional de estudantes com características de dotação e talento. Dissertação (Mestrado em Psicologia). 124f. Programa de Pós-Graduação em Psicologia, Universidade Federal de Juiz de Fora, 2011.

LIMA, D. M. M. P. O professor universitário frente às estratégias de identificação e atendimento ao aluno com altas habilidades/superdotação. Dissertação (Mestrado em Educação). 127f. Programa de Pós-Graduação em Educação, Universidade Federal do Paraná, 2011.

LIMA, M. R. S. Inclusão escolar de alunos com altas habilidades/superdotação em escolas públicas de Teresina-PI. Dissertação (Mestrado em Educação). 122f. Programa de Pós-Graduação em Educação, Fundação Universidade Federal do Piauí, 2010.

LUSTOSA, A. V. M. F. A moral em superdotados: uma nova perspectiva. Tese (Doutorado em Psicologia). 284f. Programa de Pós-Graduação em Psicologia, Universidade de Brasília, 2004.

MACHADO, A. B. L. Realidade e Perspectivas para a Educação de Alunos com Potencial para Altas Habilidades/Superdotação na Cidade de Manaus. Dissertação (Mestrado em Educação). 168f. Programa de Pós-Graduação em Educação, Universidade Federal do Amazonas, 2007.

MAGALHÃES, M. G. M. S. Programa de Atendimento ao Superdotado da Secretaria de Estado de Educação do Distrito Federal (1991-2002): inclusão social ou tergiversação burocrática? Tese (Doutorado em Sociologia). 200f. Programa de Pós-Graduação em Sociologia, Universidade Federal do Espírito Santo Brasília, 2006.

MAIA, C. M. Brincar, não brincar: eis a questão? Um estudo sobre o brincar do portador de altas habilidades. Dissertação (Mestrado em Educação). 120f. Programa de Pós-Graduação em Educação, Universidade Federal do Rio Grande do Sul, 2000.

MAIA-PINTO, R. R; FLETH, D. S. Avaliação das praticas educacionais de um programa de atendimento a alunos superdotados e talentosos. Psicologia Escolar e Educacional. Campinas, SP: ABRAPEE, v. 8, no. 1, p. 55-66, 2004.

MALDANER, E. B. O desenho da figura humana e a identificação precoce de superdotação. Dissertação (Mestrado em Psicologia). 146f. Programa de Pós-Graduação em Psicologia, Pontifícia Universidade Católica/RS, 1996.

MARQUES, C. R. Levantamento de crianças com indicadores de altas habilidades em Jaboticabal/ São Paulo. Dissertação (Mestrado em Educação Especial). 167f. Programa de Pós-Graduação em Educação Especial, Universidade Federal de São Carlos, 2010.

MARTINS, C. S. R. A Identificação do Aluno com Potencial para Altas Habilidades/Superdotação do Sistema Educacional Adventista em Manaus. Dissertação (Mestrado em Educação). 199f. Programa de Pós-Graduação em Educação, Universidade Federal do Amazonas, 2006.

MARTINS, I. O. R. Educação Especial e a Superintendência Regional de Educação de Cariacica: um diálogo possível. Tese (Doutorado em Educação). 245f. Programa de Pós-Graduação em Educação, Universidade Federal do Espírito Santo, 2011.

MELO, M. A. F. Avaliação das práticas pedagógicas desenvolvidas em Matemática em um programa de atendimento a alunos portadores de altas habilidades. Dissertação (Mestrado em Educação). 90f. Programa de Pós-Graduação em Educação, Universidade Católica de Brasília, 2005

MONTE, P. M. A aprendizagem do adolescente com altas habilidades: um estudo de caso na perspectiva da teoria da subjetividade. Dissertação (Mestrado em Educação). 167f. Programa de Pós-Graduação em Educação, Fundação Universidade Federal do Piauí, 2009. 
MORAES, C. L. S. S. Altas Habilidades/Superdotação em crianças e adolescentes negros. Dissertação (Mestrado em Psicologia). 109f. Programa de Pós-Graduação em Psicologia, Universidade Salgado de Oliveira, 2009.

MOREIRA, G. E. Perfeccionismo em adolescentes superdotados atendidos em um programa para alunos com altas habilidades/talentosos. Dissertação (Mestrado em Educação). 84f. Programa de PósGraduação em Educação, Universidade Católica de Brasília, 2005.

MOURA, L. A. Da classificação à promoção da aprendizagem: avaliação de alunos com altas habilidades. Dissertação (Mestrado em Educação). 154f. Programa de Pós-Graduação em Educação, Universidade Federal do Ceará, 2009.

NARDI, R. G. Ressignificando a educação especial a partir da complexidade e do pensamento ecosistêmico. Teses de doutorado, Pontifícia Universidade Católica de São Paulo, 2007.

NEGRINI, T. A escola de surdos e os alunos com altas habilidades/superdotação: uma problematização decorrente do processo de identificação das pessoas surdas. Dissertação (Mestrado em Educação). 15lf. Programa de Pós-Graduação em Educação, UFSM, 2009.

NICOLOSO, C. M. F. Questões norteadoras a uma proposta de atendimento a portadores de altas habilidades: Conceituação, a definição de Joseph Renzulli e sugestões de currículo. Dissertação (Mestrado em Educação). 138f. Programa de Pós-Graduação em Educação, UFSM 2002.

OLIVEIRA, C. G. Altas habilidades na perspectiva da subjetividade. Dissertação (Mestrado em Educação). 174f. Programa de Pós-Graduação em Educação, Fundação UFMS, 2007.

OLIVEIRA, L. V. Sala de recursos e o desenvolvimento da linguagem escrita. Dissertação (Mestrado em Educação). 130f. Programa de Pós-Graduação em Educação, UEM, 2009.

OLIVEIRA, M. P. Expectativas da família em relação à escolarização do seu filho com altas habilidades. Dissertação (Mestrado em Educação). 110f. Programa de Pós-Graduação em Educação, UFSM, 2009.

OLIVEIRA, R. G. Uma perspectiva em avaliação educacional baseada na teoria triárquica da inteligência humana de Roberj J. Sternberg. Dissertação (Mestrado em Educação). 147f. Programa de Pós-Graduação em Educação, Universidade do Estado do Rio de Janeiro, 1998.

OSOWSKI, C. I. Os chamados superdotados: a produção de uma categoria social na sociedade capitalista. Tese (Doutorado em Educação). 286f. Programa de Pós-Graduação em Educação, UFRS, 1989.

OUROFINO, V. T. A. T. Características cognitivas e afetivas entre alunos superdotados, hiperativos e superdotados/hiperativos: Um estudo comparativo. Dissertação (Mestrado em Psicologia). 142f. Programa de Pós-Graduação em Psicologia, Universidade de Brasília, 2005.

Superdotados e Superdotados Underachievers: Um Estudo Comparativo das Características Pessoais, Familiares e Escolares. Tese (Doutorado em Processos de Desenvolvimento Humano e Saúde). 24lf. Programa de Pós-Graduação em Processos de Desenvolvimento Humano e Saúde, Universidade de Brasília, 2011.

PALFREY, J.; GASSER, U. Nascidos na era digital: entendendo a primeira geração de nativos digitais. Porto Alegre: Artmed, 2011.

PELLEGRINO, V. B. Dinâmica familiar e atendimento a adolescentes com altas habilidades e talentos. Dissertação (Mestrado em Psicologia). 140f. Programa de Pós-Graduação em Psicologia, Universidade Salgado de Oliveira, 2008.

PERAINO, M. A. C. Adolescente com altas habilidades /superdotação de um assentamento rural: um estudo de caso. Dissertação (Mestrado em Psicologia). 105f. Programa de Pós-Graduação em Psicologia, Universidade Católica Dom Bosco, 2007.

PÉREZ, S. G. P. B. Mitos e crenças sobre as pessoas com altas habilidades: alguns aspectos que dificultam o seu atendimento. Cadernos de Educação Especial, Santa Maria, v.2, n.22, p. 45-59, 2003.

Gasparzinho vai à Escola: um estudo sobre as características do aluno com altas habilidades produtivo-criativo. Dissertação (Mestrado em Educação). 179f. Programa de Pós-Graduação em Educação, Pontifícia Universidade Católica do Rio Grande do Sul, 2004.

. Ser ou não ser, eis a questão: os processos de construção da identidade na pessoa com altas habilidades/superdotação adulta. Tese (Doutorado em Educação). 230f. Programa de Pós-Graduação em Educação, Pontifícia Universidade Católica do Rio Grande do Sul, 2008.

Revista Educação Especial | v. 27 | n. 49 | p. 353-372| maio/ago. 2014 
PEREIRA, C. E. S. Identificação de estudantes talentosos: uma comparação entre as perspectivas de Renzulli e Güenther. Dissertação (Mestrado em Psicologia). 149f. Programa de Pós-Graduação em Psicologia, Universidade Federal de Juiz de Fora, 2010.

PEREIRA, V. L. P. A Inclusão Educacional do Aluno Superdotado nos Contextos Regulares de Ensino. Dissertação (Mestrado em Educação). 118f. Programa de Pós-Graduação em Educação, Universidade Católica de Brasília, 2008.

PERIN, E. D. Investigando Potencial para Altas Habilidades em Jovens Autores de Ato Infracional. Dissertação (Mestrado em Educação). 10lf. Programa de Pós-Graduação em Educação, Universidade Federal do Amazonas, 2008.

PERIPOLLI, A. Criatividade: caminho desenhante para altas habilidades/superdotação do adolescente em conflito com a lei. Dissertação (Mestrado em Educação). 190f. Programa de Pós-Graduação em Educação, Universidade Federal de Santa Maria, 2010.

PINHO, M. C. G. O papel da escola na estruturação do autoconceito de alunos superdotados. Dissertação (Mestrado em Psicologia). 90f. Programa de Pós-Graduação em Psicologia, Universidade Federal do Rio de Janeiro, 1997.

PINTO, R. R. M. Avaliação das práticas educacionais implementadas em um Programa de Atendimento a Alunos Superdotados e Talentosos. Dissertação (Mestrado em Psicologia). 128f. Programa de Pós-Graduação em Psicologia, Universidade de Brasília, 2002.

PIRES, D. D. A. A Representação Social da Inteligência em Familiares de Adolescentes Considerados Super-Dotados. Dissertação (Mestrado em Psicologia). 118f. Programa de Pós-Graduação em Psicologia, Pontifícia Universidade Católica de Goiás, 2002.

RABELO, M. V. P. Altas Habilidades/Superdotação: Necessidades formativas dos professores de ciências na perspectiva da educação inclusiva. Dissertação (Mestrado em Educação em ciências e matemática). 112f. Programa de Pós-Graduação em Educação em ciências e matemática, Universidade Federal de Goiás, 2010.

RANGNI, R. A. O atendimento às pessoas com altas habilidades no Estado de São Paulo. Dissertação (Mestrado em Educação). 16lf. Programa de Pós-Graduação em Educação, Universidade Cidade de São Paulo, 2005.

RANGNI, R. A.; COSTA, M. P. R. Altas habilidades/superdotação: entre termos e linguagens. Revista Educação Especial, Santa Maria, v. 24, n. 41, p. 467-482, set./dez. 2011.

RECH, A. J. D. Estudo de caso de uma criança com características de altas habilidades: problematizando questões referentes à inclusão escolar. Dissertação (Mestrado em Educação). 93f. Programa de PósGraduação em Educação, Universidade Federal de Santa Maria, 2007.

REIS, A. P. P. Z. Representação Feminina em Um Programa de Atendimento às Altas Habilidades/ Superdotação. Dissertação (Mestrado em Educação). 102f. Programa de Pós-Graduação em Educação, Universidade Católica de Brasília, 2008.

REIS, E. Superdotação e psicanálise: uma questão do desejo. Dissertação (Mestrado em Psicologia escolar e do desenvolvimento humano). llof. Programa de Pós-Graduação em Psicologia escolar e do desenvolvimento humano, Universidade de São Paulo, 2001.

REIS, H. M. M. S. A. Cidadania e exclusão: a representação social da inteligência em portadores de altas habilidades. Dissertação (Mestrado em Educação). 119f. Programa de Pós-Graduação em Educação, Universidade do Estado do Rio de Janeiro, 2001.

Educação Inclusiva é para todos? A (falta de) formação docente para Altas Habilidades/ Superdotação no Brasil. Tese (Doutorado em Educação). 267f. Programa de Pós-Graduação em Educação, Universidade do Estado do Rio de Janeiro, 2006.

RENZULLI, J.S. What makes giftedness? Re-examining a definition. Phi Delta Kappa, v. 60, n. 3, p. 18084, 261, nov. 1978.

RIBEIRO, V. T. A relação entre superdotado, inteligência maquiavélica e consciência moral. Dissertação (Mestrado em Psicologia). 96f. Programa de Pós-Graduação em Psicologia, Pontifícia Universidade Católica de Goiás, 2004.

ROCHA, R. C. S. O Desperdício de talentos em escolas da Rede Estadual de Ensino em Volta Redonda (RJ): algumas formas de representação social. Dissertação (Mestrado em Educação). 164f. Programa de Pós-Graduação em Educação, Universidade do Estado do Rio de Janeiro, 2002. 
SABATELLA, M. L. P. Instituto para otimização da aprendizagem - uma alternativa educacional para alunos superdotados e talentosos. Dissertação (Mestrado em Educação). 273f. Programa de Pós-Graduação em Educação, Universidade Federal do Paraná, 1995.

SAKAGUTI, P. M. Y. Concepções de pais sobre as altas habilidades/superdotação dos filhos inseridos em atendimento educacional especializado. Dissertação (Mestrado em Educação). 130f. Programa de Pós-Graduação em Educação, Universidade Federal do Paraná, 2010.

SANTOS, S. C. G. Avaliação da Personalidade de Gerentes de Alto Desempenho por meio do Método de Rorschach. Tese (Doutorado em Psicologia). 10lf. Programa de Pós-Graduação em Psicologia, Pontifícia Universidade Católica do Rio Grande do Sul, 2009.

SEVERO, A. A. Educação especial: do atendimento à gestão? Uma análise de uma fundação estadual de educação especial no Rio Grande do Sul. Dissertação (Mestrado em Educação). 130f. Programa de PósGraduação em Educação, Universidade Federal do Rio Grande do Sul, 2007.

SILVA, I. Talento acadêmico e desenvolvimento escolar: A importância da motivação no contexto educacional. Dissertação (Mestrado em Psicologia). 102f. Programa de Pós-Graduação em Psicologia, Universidade Salgado de Oliveira, 2009.

SILVA, M. L. L. Indicadores de altas habilidades entre os reclusos do centro de atendimento sócio-educativo no município de Santo Ângelo - RS. Dissertação (Mestrado em Educação). 138f. Programa de Pós-Graduação em Educação, UFSM, 2005.

SILVA, T. C. Programa de revelações e aptidões e capacidades desportivas de atletas portadores de altas habilidades: do senso comum à metacognição intuitiva. Dissertação (Mestrado em Ciência da Motricidade Humana). 264f. Programa de Pós-Graduação em Ciência da Motricidade Humana, Universidade Castelo Branco, 2003.

SIQUEIRA, I. Políticas Públicas de Educação Inclusiva a Partir da LDB: Impacto dos Princípios e Diretrizes Internacionais. Dissertação (Mestrado em Educação). 143f. Programa de Pós-Graduação em Educação, Universidade Católica de Brasília, 2009.

SISTELOS, A. J. C. M. Um ambiente computacional de apoio ao método de avaliação autêntica: projeto Poeta (Portfólio Eletrônico temporal e ativo). Dissertação (Mestrado em Informática). 139f. Programa de Pós-Graduação em Informática, Universidade Federal da Paraíba, 1999.

SOARES, A. M. I. A construção da autonomia moral e intelectual em portadores de altas habilidades. Dissertação (Mestrado em Educação). 132f. Programa de Pós-Graduação em Educação, Universidade Federal do Paraná, 2003.

SOUZA, A. C. Características Desejáveis em Professores de Alunos com Altas Habilidades/Superdotação. Dissertação (Mestrado em Educação). 76f. Programa de Pós-Graduação em Educação, Universidade Católica de Brasília, 2010.

SOUZA, J. R. S. O trabalho junto ao superdotado em nossa realidade. Dissertação (Mestrado em Psicologia da Saúde). 133f. Programa de Pós-Graduação em Psicologia da Saúde, Universidade Metodista de São Paulo, 2001.

SOUZA, P. M. Identificação e caracterização dos alunos com deficiência, transtornos globais do desenvolvimento e altas habilidades/superdotação, matriculados nas classes comuns do ensino regular, na rede pública estadual, em município do interior paulista. Dissertação (Mestrado em Psicologia). 120f. Programa de Pós-Graduação em Psicologia, Universidade de São Paulo, 2011.

SPIRDUSO, W. W. Dimensões físicas do envelhecimento. Trad. Paula Bernardi. Barueri, SP: Manole, 2005.

TRANCOSO, B. S. Percepções de alunos superdotados acerca das relações entre desenvolvimento socioemocional e desempenho acadêmico. Dissertação (Mestrado em Educação). 22lf. Programa de PósGraduação em Educação, Universidade Federal do Paraná, 2011.

TSUBOI, M. P. P. Um percurso nacional - 20 anos de estudos sobre altas habilidades/superdotação: a contribuição discente dos programas de Pós-Graduação. Dissertação (Mestrado em Educação). 218f. Programa de Pós-Graduação em Educação, Universidade do Estado do Rio de Janeiro, 2002.

VIANA, J. M. Emoção, inteligência e aprendizagem: a busca de caminhos possíveis para o desenvolvimento de altas habilidades em sala de aula. Dissertação (Mestrado em Educação). 164f. Programa de PósGraduação em Educação, Universidade do Estado do Rio de Janeiro, 2003.

Revista Educação Especial | v. 27 | n. 49 | p. 353-372| maio/ago. 2014

Santa Maria 
VIANA, T. V. Caminhos da excelência da escola pública de Fortaleza: o conceito de altas habilidades dos professores. Dissertação (Mestrado em Educação). 147f. Programa de Pós-Graduação em Educação, Universidade Federal do Ceará, 2003.

VIANA, T. V. Avaliação educacional diagnóstica: uma proposta para identificar altas habilidades. Tese (Doutorado em Educação). 324f. Programa de Pós-Graduação em Educação, UFC, 2005.

VIEGAS, L. T. Educação Especial no Rio Grande do Sul: uma análise da oferta e das políticas educacionais no período de 1988 a 2002. Dissertação (Mestrado em Educação). 119f. Programa de Pós-Graduação em Educação, Universidade Federal do Rio Grande do Sul, 2005.

VIEIRA, N. J. W. Gênio da lâmpada quebrada! Um estudo psicanalítico da relação professora-aluno portador de altas habilidades. Dissertação (Mestrado em Educação). 262f. Programa de Pós-Graduação em Educação, Universidade Federal do Rio Grande do Sul, 1999.

Viagem a "Mojave-Óki!": a trajetória na identificação das altas habilidades/superdotação em crianças de quatro a seis anos. Tese (Doutorado em Educação). 228f. Programa de Pós-Graduação em Educação, Universidade Federal do Rio Grande do Sul, 2005.

WINNER, E. Crianças superdotadas: mitos e realidades. Porto Alegre: Artes Médicas, 1998.

\section{Correspondência}

Miguel Claudio Moriel Chacon - Universidade Estadual Paulista Júlio de Mesquita Filho, Faculdade de Filosofia e Ciências - Campus de Marília, Departamento de Educação Especial. Avenida Higyno Muzzy Filho, 737, CEP: 17525-900, Caixa-postal: 420 - Marilia, São Paulo - Brasil.

E-mail:profmcmchacon@gmail.com - barbara.amts@gmail.com

Recebido em 19 de junho de 2013

Aprovado em 02 de setembro de 2013 